\title{
Ischemia of the glans penis following circumcision: Case report and revision of the literature
}

\author{
Pietro Pepe, Francesco Pietropaolo, Giuseppe Candiano, Michele Pennisi \\ Urology Unit, Cannizzaro Hospital, Catania, Italy.
}

\begin{abstract}
Summary Ischemic complications of the glans penis are rare and commonly result from trauma, inadvertent administration of vasoconstrictive solutions, diabetes mellitus, circumcision and vasculitis; we refer about a young man with severe ischemia of the glans penis following circumcision. The patient had undergone circumcision 5 days before in a surgery department under local anesthesia (1\% mepivacaine hydrochloride).

The patient noticed a brownish color and edema of the glans penis at $24 \mathrm{~h}$ after he opened the wound dressing, but arrived to our hospital only 5 days after circumcision because these findings had progressed. Physical examination revealed the black color or necrotic appearance of the glans penis, and edema on the dorsal penile skin.

The patient underwent antibiotic, antiplatatelet, corticosteroid and iperbaric therapy achieving a complete restitutio ad integrum.
\end{abstract}

KEY WORDS: Ischemia of the glans penis; Circumcision complications; Glans penis.

Submitted 1 September 2014; Accepted 30 November 2014

\section{INTRODUCTION}

Ischemic complications of the glans penis are rare and commonly result from trauma, inadvertent administration of vasoconstrictive solutions, diabetes mellitus, circumcision and vasculitis (1-6).

We refer about a young man with severe ischemia of the glans penis following circumcision.

\section{Case report}

A 20-year-old man was admitted to our hospital with complaints of black color and swelling of the glans penis. The patient had undergone circumcision 5 days before in a surgery department under local anesthesia (1\% mepivacaine hydrochloride) and was discharged 12 hours following circumcision. The patient noticed a brownish color and edema of the glans penis at $24 \mathrm{~h}$ after he opened the wound dressing, but arrived to the hospital only 5 days after circumcision because these findings had progressed. Physical examination revealed the black color or necrotic appearance of the glans penis, and edema on the dorsal penile skin (Figure 1a); moreover colorDoppler ultra- sound of the penis was normal. There were no urination problems and all laboratory findings, including whole blood count, blood chemistry, and bleeding-clotting profile were within normal limits. The patient underwent antibiotic (1 tablet of levofloxacin 500 daily for 15 days), antiplatatelet (1 tablet of aspirin $330 \mathrm{mg}$ daily for 1 month), corticosteroid (prednisone $25 \mathrm{mg}$ daily for 10 days) and iperbaric therapy (for 15 days) and achieved a complete restitutio ad integrum (Figure 1b).

\section{Figure 1.}

Severe ischemia of the glans penis (1a) at clinical admission (5 days after circumcision); normal color and trophism of the glans (1b) after medical treatment (15 days later)

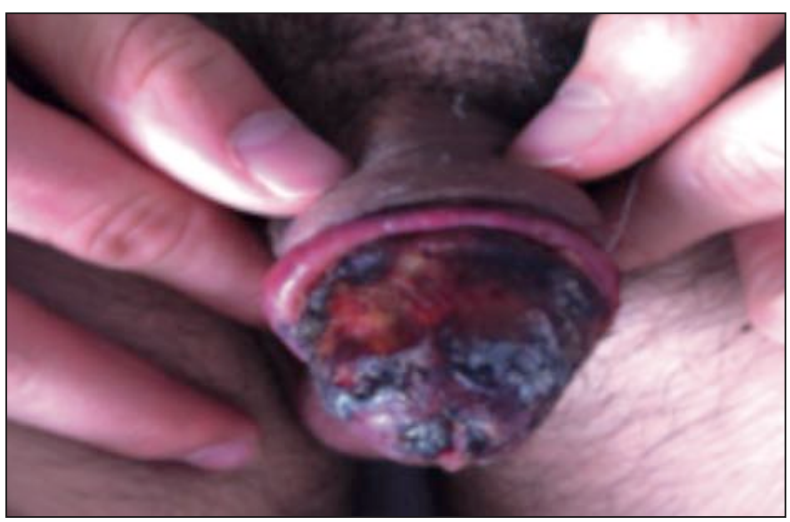

a.

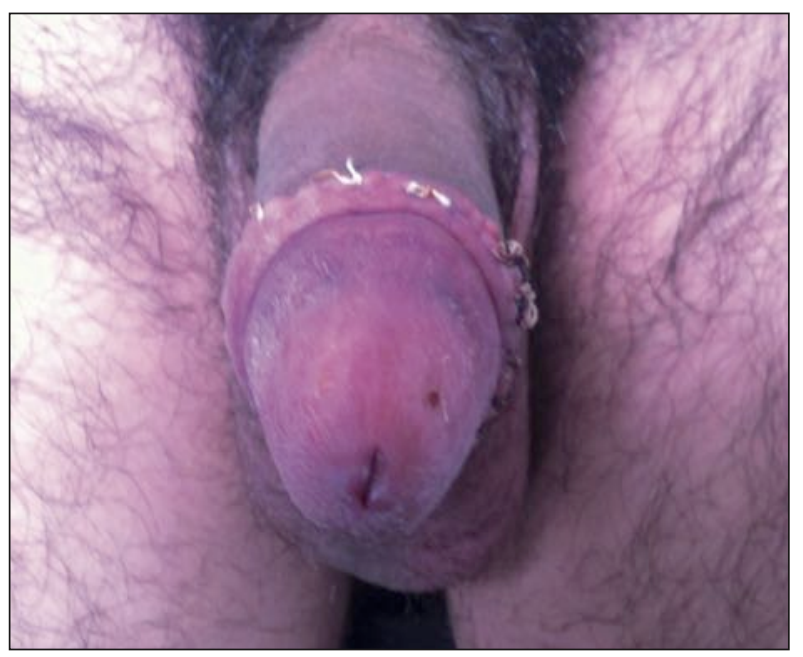




\section{Discussion}

Ischemia of the glans penis is a rare condition; the most frequent causes are circumcision, trauma, penile strangulation, and application of vasoconstrictive agents (1-6). Additionally, there are several pathologies which cause glanular ischemia or necrosis in adults, including diabetes mellitus (7), acute arterial occlusion, foreign bodies, Fournier's gangrene, spider bite (8) and topical treatment with $1 \%$ gentian violet (9). Ischemia of the glans penis following circumcision commonly results from dorsal penile nerve block with local anesthetics $(3,4)$ and inadequate surgical technique or devices.

The main goal of the treatment is to provide sufficient blood flow and oxygen delivery to the ischemic penis. Burke et al. (3) described ischemia of the glans penis occurring $40 \mathrm{~min}$ after dorsal penile nerve block with $0.75 \%$ ropivacaine, and successfully treated with an intravenous infusion of iloprost.

Broughton et al. (8) reported that hyperbaric oxygen and methylprednisolone treatment was an effective treatment for a patient with glanular skin necrosis due to spider bite. On the other hand, penile necrosis in patients with diabetes mellitus and Fournier's gangrene may need aggressive surgical debridement and partial penectomy following hyperbaric oxygenation. The literature reports cases in which pentossifillina (PTX), an orally active hemorheological agent which is widely used to treat peripheral vascular and cerebrovascular diseases, was used in the treatment of post-circumcisional ischemia of the glans penis $(1,10)$; it was suggested that the valuable effect of PTX on ischemia-reperfusion injury might be related to the stimulation of prostaglandin production, and inhibition of the phosphodiesterase activity, which led to cAMP synthesis. Aslan et al. (10) encountered a similar clinical picture in a case of ischemia of the glans on the third day after circumcision; moreover, Tzeng et al. (11) treated a 33-year-old patient with PTX and hyperbaric oxygen therapy and reported that the ischemia resolved completely.

Recently, Efe et al. (12) reported a case of severe glans ischemia occurred 24 hours after circumcision with local anesthesia ( $0.1 \%$ xylocaine containing ephedrine) in a children 7 years old that was successfully treated with subcutaneous injection of enoxaparin (low-molecularweight heparin) for 5 days.
In the presented case, although the precise cause of the severe glanular ischemia was not known, it might have been secondary to the circumferential nerve block or very firm wound dressing for $24 \mathrm{~h}$; anyway, medical therapy (aspirin, prednisone and antibiotic) combined with hyperbaric oxygen treatment allowed to achieve a complete restitutio ad integrum.

\section{References}

1. Karaguzel E, Tok DS, Kazaz IO, et al. Postcircumcisional ischemia of the glans penis treated with pentoxifylline. Case Rep Urol. 2013; 2013:278523.

2. Wiliams N, Kapila L. Complications of circumcision. Br J Surg. 1993; 80:1231-1236.

3. Burke D, Joypaul V, Thomson MF. Circumcision supplemented by dorsal penile nerve block with $0.75 \%$ ropivacaine: a complication. Reg Anesth Pain Med. 2000; 25:424-427.

4. Soh CR, Ng SBA, Lim SL. Dorsal penile nerve block. Paediatr Anaesth. 2003; 13:329-333.

5. Brecheteau F, Grison P, Abraham P, et al. Successful medical treatment of glans ischemia after voluntary buprenorphine injection. J Sex Med. 2013; 10:2866-2870.

6. Pepe P, Panella P, Candiano G, et al. Partial priapism secondary to idiopathic segmentary thrombosis of corpora cavernosa. Arch Ital Urol Androl. 2012; 84:101-103.

7. Nomura T, Sakamoto F. A case of penile necrosis in a patient with diabetes mellitus. Nippon Hinyokika Gakkai Zasshi. 1992; 83:1138-1141.

8. Broughton $G$. Management of the brown recluse spider bite to the glans penis. Mil Med. 1996; 161:627-629.

9. Zabala Egurrola JA, Pertusa Peña C, Arruza Echevarría A, et al. Glans penis necrosis secondary to gentian violet treatment. Arch Esp Urol. 1989; 42:800-802.

10. Aslan A, Karaguzel G, LU MM. Severe ischemia of the glans penis following circumcision: A successful treatment via pentoxifylline. Int J Urol. 2005; 12:705-707.

11. Tzeng YS, Tang SH, Meng E, Lin TF, Sun GH. Ischemic glans penis after circumcision. Asian J Androl. 2004; 6:161-163.

12. Efe E, Resim S, Bulut BB, et al. Successful treatment with enoxaparin of glans ischemia due to local anesthesia after circumcision. Pediatrics. 2013; 131:e608-11.

Correspondence

Pietro Pepe, MD

piepepe@hotmail.com

Francesco Pietropaolo, MD

Giuseppe Candiano, MD

Michele Pennisi, MD

Urology Unit, Cannizzaro Hospital

Via Messina 829 - Catania, Italy

Fax ++ 39957263259 